\title{
La lectura del posestructuralismo en Manfred Frank. El debate franco-alemán
}

\author{
Naim Garnica \\ CONICET/Universidad Nacional de Catamarca/Instituto de Investigación \\ en Teorias del Arte y Estética
}

Resumen: El ensayo pretende reconstruir la lectura del pensamiento francés en las lecciones dictadas por Manfred Frank en su texto ¿Qué es el neoestructuralismo? Estas lecciones fueron claves para la recepción alemana del pensamiento francés surgido en los años 60. Las lecciones de Frank parecen mostrar algunas vías productivas para pensar la recepción alemana del posestructuralismo sin caer en el rechazo que llevó adelante el trabajo de Jürgen Habermas en El discurso filosófico de la modernidad. Nuestro análisis se centra en la problemática de la subjetividad, tanto en las impugnaciones que realiza Frank, como también en aquellos puntos destacados que podría evidenciar el posestructuralismo. Finalmente, el trabajo sugiere, mediante el camino marcado por las lecciones de Frank, la existencia de una recepción menos problemática en el plano de la estética alemana.

Palabras clave: subjetividad; Modernidad; romanticismo; estética; post-estructuralismo

\begin{abstract}
The Reading of Post-structuralism in Manfred Frank. The GermanFrench Debate". The essay aims to reconstruct the reading of French thought by focusing on the lessons developed by Manfred Frank in his text What is Neo-structuralism? These lessons were key to the German reception of the French thought that emerged in the 60s. Frank's lessons seem to offer some productive ways to think about the German reception of post-structuralism without falling into the rejection that led to the work of Jürgen Habermas in The Philosophical Discourse of Modernity. Our analysis focuses on the problem of subjectivity, which involves both the challenges that Frank proposes and the points that could be evidenced by poststructuralism. Finally, through the path marked by the lessons of Frank, the work suggests the possibility of a less problematic reception in the plane of German aesthetics.
\end{abstract}

Keywords: subjectivity; Modernity; romanticism; aesthetics; post-structuralism 


\section{Introducción: Manfred Frank y el neoestructuralismo}

A comienzos de los años 80 en Düsseldorf, el teórico de la literatura Manfred Frank dicta alrededor de veintisiete lecciones dedicadas a la explicación, problematización y cuestionamiento de la filosofia francesa. Estas lecciones serán publicadas originalmente en alemán bajo el nombre Was ist Neostrukturalismus? en 1984 (posteriormente traducida al inglés en 1989¹). Esta obra constituye uno de los primeros intentos de la filosofía alemana contemporánea de acercarse al pensamiento francés producto de los años 60. A su vez, es una de las obras más reveladoras sobre la posición de Manfred Frank en torno a sus preocupaciones actuales. En términos generales, el texto muestra, por una parte, que su lectura reconstructiva -procedimiento denominado por Frank como hermenéutica constructiva- del neoestructuralismo se encuentra determinada por la hermenéutica de Schleiermacher. Mientras que, por otra parte, su cuestionamiento de los conceptos de historia y subjetividad estarían orientados desde los supuestos del neoidealista Dieter Henrich, quien le permite reconsiderar y cuestionar los conceptos de conciencia, autoconciencia y sujeto del neoestructuralismo².

También puede advertirse en las lecciones de Frank que Sartre, la lectura de Peter Szondi sobre el romanticismo alemán y los propios románticos (Novalis, el joven Schelling y el joven Friedrich Schlegel) son un recurso de anticipación respecto de las "hipotéticas" novedades que el neoestructuralismo viene a develar. Lejos de considerarlo un pensamiento rupturista, Frank observa las distintas continuidades, analogías y paralelismos que los planteos de autores franceses tienen con tradiciones filosóficas anteriores, fundamentalmente alemanas. Un lector atento de estas veintisiete lecciones y un apéndice no puede dejarse llevar por la exposición del autor, aparentemente neutral y fiel

\footnotetext{
1 La edición original es Frank, M., Was ist Neostrukturalismus?, Fráncfort d.M.: Suhrkamp, 1984. La versión inglesa fue publicada como Frank, M., What is Neostructuralism?, Minéapolis: University of Minnesota Press, 1989.

2 En algunas clasificaciones y discusiones recientes sobre la subjetividad, suele colocarse a Henrich y a Frank como los representantes de la Escuela de Heidelberg, cuya defensa del sujeto no sería mediante las opciones de la critica a la modernidad ni su defensa a ultranza. Esta clasificación es seguida por López Lizaga (“¿Tiene la autoconciencia un fundamento lingüístico? Ernst Tugendhat y la Escuela de Heidelberg”, en: Logos. Anales del Seminario de Metafisica, v. XLVI, (2013), pp. 77-101) en otro marco de discusión, pero muestra la cercanía en el trabajo de ambos autores.
} 
a los textos de los autores en cuestión, pues perdería de vista las críticas de fondo al neoestructuralismo. Aunque la organización del texto se encuentre orientada a informar, enseñar y difundir las obras de los posestructuralistas como Foucault, Deleuze, Derrida ${ }^{3}$, Althusser y Lacan, a su vez constituye la elaboración de una incipiente teoría del sujeto que luego se desarrollará en otros textos de Frank a partir de sus consideraciones sobre la individualidad ${ }^{4}$.

La apertura y el final del texto intenta plantear un diálogo ${ }^{5}$ francoalemán que en los años 80 parecía haberse desvanecido, más del lado alemán que del francés, en las dos corrientes predominantes de la filosofia alemana: la Teoría Crítica y la Hermenéutica. Su intención es recordarle a la filosofía europea "su compromiso a favor de lo universal"6. El propósito del autor era bastante curioso, pues se permite vincular planteos que a golpe de vista no son semejantes. Por ejemplo, Frank sugiere que el concepto de historia como a priori histórico de Foucault ya habría estado planteado en Friedrich Schlegel ${ }^{7}$ y la lingüística alemana al preguntarse por el lenguaje como lo "históricamente trascendental". Incluso, el concepto de "suplementariedad" de Derrida posee

3 Derrida (Psyche: inventions de 1'autre, París: Gallile, 1988) ha sido uno de los autores que con mayor énfasis se ha opuesto a la clasificación de los post. Pese a que Frank les asignará el neo, Derrida parece estar oponiéndose a cualquier tipo de clasificación de su pensamiento.

4 En La piedra de toque de la individualidad (1995), Manfred Frank plantea algunas variantes en relación a las lecciones. En la Introducción, Frank no dudará en reconocer a la teoría del sujeto neoestructuralista junto a las tesis irracionalistas y conservadoras de Alemania, como las de Klages, Baeumler y Spengler, sobre la muerte del hombre. Una convergencia similar, le parece a Frank, muestra tanto la política conservadora como la pretensión fascista de remontarse a fuentes irracionales y primitivas que en la República de Weimar llevaron al surgimiento del nazismo ( $C f$. Frank, M., La piedra de toque de la individualidad. Reflexiones sobre sujeto, persona e individuo con motivo de su certificado de defunción postmoderno, Barcelona: Herder, 1995, pp. 9-10). A diferencia de las lecciones que repasaremos, el neoestructuralismo en este texto es sentado en el banquillo de acusados y visto como uno de los responsables del regreso de la política conservadora de derecha. Frank señala que, en relación al cuestionamiento del sujeto, desde Adorno y Heidegger hasta el neoestructuralismo, "no se trataba propiamente de un problema filosófico sensu stricto, sino de un problema paralelo al nuestro: el de describir el ascenso incesante de la derecha política, no simplemente en el gesto de una descongestión de la izquierda. Las visiones fascistas del mundo -en cuya prehistoria ciertamente ha jugado, y sigue jugando todavia hoy, un papel inolvidable el deseo de abdicación del sujeto soberano y autónomo- solo tienen posibilidades en las sociedades tardoburguesas de enorme complejidad, cuando la conciencia de amplios estratos de la población no mantienen el paso con la evolución de las fuerzas productivas" (ibid., p. 11).

En la lección final, Frank convoca a los participantes de su clase a ver cómo su intención fue establecer una "disposición hermenéutica para entablar una conversación con el neoestructuralismo" (Frank, M., ¿Qué es el neoestructuralismo?, México D.F.: FCE, 2011, p. 486).

6 Ibid., p. 11.

7 En su argumento sobre la preocupación foucaultiana de la historia al inicio de la Lección 10, Frank indica: "En realidad, la noción de lo 'históricamente o empíricamente trascendental' se encuentra, desde el romanticismo (Friedrich Schlegel) hasta llegar a Jürgen Habermas, en los textos esenciales de la formación de la teoria de las ciencias humanas" (ibid., p. 176). 
un antecedente en el reconocimiento de la crítica del arte romántica sobre la obra de arte como una carencia que debe ser complementada por la crítica ${ }^{8}$. El recurso de asociar nombres y conceptos entre filósofos alemanes y franceses, por momentos reduccionista, y por otros, cercano a un "nacionalismo filosófico" en el disfraz de ya lo había señalado..., aparece con frecuencia en el movimiento del diálogo.

Frank sostiene que sus lecciones están dedicadas a establecer un diálogo profundo con el neoestructuralismo. Sin embargo, ellas evidencian un conjunto de objeciones al neoestructuralismo debido a la lectura de la tradición filosófica que él mismo lleva a cabo ${ }^{9}$. Tales objeciones acompañan casi la totalidad del texto y solo es condescendiente en muy pocas ocasiones. La organización de las lecciones se lleva a cabo gracias a la distinción de tres momentos o preguntas al neoestructuralismo: a) ¿de qué modo se manifiesta con respecto al fenómeno de la historia? (Lecciones 6 a 12); b) ¿cómo explica el fenómeno de la subjetividad? (Lecciones 12 a 24); y c) ¿de qué teoría de la formación de signos y de los efectos sensoriales dispone? (Lección 25 hasta el final). Además, hay un Apéndice dedicado a Derrida donde Frank muestra una lectura romántica del concepto de diseminación al compararlo con la ironía romántica de Schlegel y Solger.

Antes de ocuparnos de este vínculo entre romanticismo y neoestructuralismo, donde creemos se abre una vía no reactiva del pensamiento alemán en relación a la filosofía francesa, repasemos algunas de las críticas e impugnaciones más importantes del autor. Estas críticas son numerosas, por ello, nos concentraremos en la categoría de subjetividad. Esta noción cifra, en gran medida, no solo las críticas más duras de Frank al posestructuralismo, sino

8 En la lección 4, Frank sostiene que Derrida toma su idea de suplementariedad de Lévi-Strauss. Pese a esa herencia estructuralista, Frank indica: "En el campo de la crítica artística lo reconocieron así los primeros románticos que consideraban a la crítica literaria como complemento de una irreductible carencia en la obra de arte misma. Derrida está muy cerca de esta idea. El movimiento de la significación dice -y yo arreglo: también el de la interpretación- añade algo, es lo que hace que haya siempre 'más' pero esa edición es flotante porque viene a ejercer una función vicaria, a suplir una falta por el lado del significado (ED, 397). Por tanto: toda interpretación -e incluso, cada utilización de signos- presenta de alguna manera una propuesta de cómo se podría sustituir el sentido central faltante del texto, y con ello definirlo (de forma provisional con reservas)" (ibid., p. 80).

9 Robert Holub, en su reseña de la versión original del texto, sostiene que los teóricos alemanes se oponen a la teoría francesa sin saber demasiado a qué es lo que se oponen. Indica: "Si bien es cierto que el post-estructuralismo, sobre todo en algunas de sus manifestaciones más extremas nos ha proporcionado frecuentemente, en lugar de desalentarnos, estas respuestas equivocadas, el rechazo del pensamiento francés contemporáneo es, sin embargo, lamentable y ha contribuido al creciente aislamiento de la teoría y los teóricos alemanes de la escena crítica estadounidense" (Holub, R., "Review: Was is Neostructuralism?", en: The German Quarterly, v. LIX, 1 (1985), p. 112). 
que además revela algunos de los supuestos de las lecciones. Cabe señalar que nos limitaremos a repasar la posición de Frank sin establecer ni las posibles respuestas de los pensadores franceses ni tampoco los equívocos en que el autor podría incurrir en su lectura de ellos.

\section{El neoestructuralismo y sus fuentes: estructuralismo y subjetividad}

Antes de llegar a las interrogantes antes indicadas, Frank nos conduce por una revisión de las fuentes que informa la crítica posestructuralista a la subjetividad y modernidad. En primer lugar, analiza las herencias teóricas del pensamiento elaborado por los filósofos franceses (Lacan, Althusser, Foucault, Deleuze y Derrida), el cual se encuentra lejos de ser una ruptura definitiva con el estructuralismo clásico. En segundo lugar, se ocupa de las fuentes que informan la crítica a la modernidad y la subjetividad, como Nietzsche y Heidegger. En este apartado nos ocupamos del primer punto y en el apartado siguiente del segundo.

Si en la versión norteamericana de la filosofia francesa se intentó señalar que la inauguración del posestructuralismo venía a marcar el final o la superación del estructuralismo, Frank coloca el neo- para indicar que no hay tal distinción. Por ese motivo, el autor bautiza a este movimiento con el prefijo neo- y no post-, dado que entiende que existen más continuidades de las que podemos suponer, por ejemplo, entre Saussure y Derrida. En las primeras lecciones, Frank expone que el diálogo interno del neoestructuralismo con el estructuralismo clásico, a pesar de que este último se concibe a sí mismo como un pensamiento post-metafísico, plantea una convergencia entre ambos. En esa dirección afirma que los trabajos del neoestructuralismo le deben más de lo que enuncian a Saussure y Levi-Strauss. Respecto de Saussure, identifica un problema con su recepción. La versión oficial del Curso de lingüística general presentaba rasgos distintivos de una semiología estructural que buscaba controlar el lenguaje en una estructura esquemática de síntesis entre significado y significante, entre la idea y su material sonoro. Una versión de esta naturaleza acercaba a Saussure a las consideraciones de filósofos idealistas como Kant, que buscan en la sintesis entre concepto e intuición la respuesta a las posibilidades que el sujeto tiene para referirse a la experiencia sensorial.

Sin embargo, la evidencia póstuma de Saussure lo muestra cerca de las teorizaciones del lenguaje de Humboldt, Schleiermacher y el joven Schelling. En ese contexto, deben distinguirse dos puntos esenciales en Saussure. El primero, relacionado a que la lengua no es sustancia sino forma y, el segundo, que su 
concepto de estructura debe ser entendido en clave de un juego diferencial de negaciones. Ambos puntos se encontrarán en las reflexiones de Derrida, pero modificados de un modo u otro. Con esto, Frank no pretende diluir a Derrida en Saussure; por el contrario, procura indicar las condiciones de posibilidad que Saussure permitió para la emergencia del neoestructuralismo. Aunque su coincidencia es fundamental, ya que ambos entienden la ausencia de limites en las oposiciones y diferencias en el lenguaje, la distancia entre ellos evidencia el tránsito hacia el neoestructuralismo. Frank reconoce en relación a Saussure que el juego diferencial puede ser unificado en una conciencia colectiva. Tal unificación sería entendida por los neoestructuralistas como una forma de vigilancia del lenguaje que controla la identidad de la estructura. De ese modo, dicha característica coincidiría con la metafísica y la negación del Otro que no estaría dispuesta a aceptar la iteración diferenciadora que se produce en la identidad unificadora del signo. En este punto, Frank no desconoce la crítica derridiana al estructuralismo de Saussure. De hecho, indica hegelianamente que la iteración de la diferancia sería lo que provocaría una temporalidad de espaciamiento diferencial que "frustra su presencia ante sí mismo. Porque el tiempo es -según una famosa definición de la Enciclopedia de Hegel- 'el Ser que, al ser, no es, y al no ser, es', es decir, la contradicción existente a la no presencia existente"10.

En esta línea teórica, el límite del estructuralismo clásico será marcado por la aparición de la antropología de Lévi-Strauss, que observa la posibilidad de transformación de la estructura a partir del mito. La antropología de LéviStrauss pondría el acento en los contenidos de la estructura, la cual mantiene como matriz la identidad de las transformaciones. Esto supone considerar que la estructura no puede surgir de algo no estructural. Según Frank, dicho planteo encuentra ecos pasados en el reparo casi bíblico de Schleiermacher acerca de que "ninguna forma de nueva invención es absolutamente nueva"11. Entonces, Lévi-Strauss compartiría con la tradición heideggeriana de la historia que las estructuras o epistemes cambian, pero no pueden ser algo absolutamente nuevo, pues se mantienen como continuidad regida por una matriz. A diferencia del modelo clásico, la estructura tiene la posibilidad de desplazarse y variar, en la medida en que excluya un corte radical surgido de la exterioridad de la estructura. Frank denomina estructuralismo transformacional a este modelo. Su

10 Frank, M., ¿Qué es el neoestructuralismo?, p. 92.

11 Ibid., p. 70. 
novedad radicaría en la modificación: "las cartas de la estructura... tienen que ser cambiadas constantemente por aquellas que superan mejor la situación o la interpretan más acertadamente... ellas se descubren como lo que en el fondo siempre fueron: como variantes o transformaciones de una estructura..."12. Así, si en virtud de la historicidad y la modificación de los contenidos de la estructura la fluidez aparece en la estructura, ¿dónde puede encontrarse su centro? ¿En qué lugar se hallaría su unidad e identidad? De algún modo, el planteo de la antropología estructural abre la interrogante acerca de la existencia de una estructura sin un centro organizador. Este argumento sería decisivo para el neoestructuralismo, dado que muestra el desplazamiento de la estructura frente a la falta de un principio ordenador, como en la metafísica. Ella consistia, según el neoestructuralismo, en poder vincular tres aspectos: la existencia de un mundo trascendente, un pensamiento por medio de principios y el conocimiento científico con el objetivo de dominar y controlar su objeto, lo cual desembocaba en una voluntad de poder como voluntad de verdad. Este deseo podía no solo advertirse en la metafisica, sino también en el estructuralismo clásico, el cual, a diferencia del estructuralismo transformacional, guarda la suposición de que la estructura controla a sus elementos.

A partir de esas dos derivaciones estructuralistas, Frank intenta mostrar que las consecuencias del estructuralismo clásico y la antropología estructural o estructuralismo transformacional preparan la escena neoestructuralista. Pese a ello, Frank deja percibir la observación de que el neoestructuralismo sería una variación rebelde de una misma secta ${ }^{13}$. Igualmente, con el correr de la exposición tal consideración se disipa al marcar las distancias, en particular, con el estructuralismo clásico. La bisagra entre estructuralismo y neoestructuralismo, en la reconstrucción de Frank, puede entenderse en virtud de que la estructura necesita ser pensada como descentralizada. La inclusión que Derrida lleva a cabo de una estructura sin centro se aleja de un significado trascendental a los fines de incluir a la significación en un juego infinito en su

\footnotetext{
12 Ibid., p. 71.

${ }^{13}$ Luego del análisis que comentamos, Frank reinicia la sesión de sus clases indicando que, en virtud de estos análisis, se podría lograr entrever una definición de neoestructuralismo. Indica: "El neoestruturalismo radicaliza la idea fundamental de Saussure de acuerdo con la cual el sentido de los discursos a través de los cuales nos entendemos unos con otros se fundamenta, por una parte, en algo que en sí mismo no es significativo, es decir, en el juego diferencial de los Saussure tardío llama semas, y Derrida llama marcas o 'marcas no presentes'. La idea estructuralista fundamental está radicalizada..." (ibid., p. 93). En este pasaje, Frank parece establecer una equiparación categorial entre los dos autores para volver a insistir en su analogía entre estructuralismo y neoestructuralismo.
} 
extensión. La privación de un centro no admite pensarlo como algo preexistente y necesario como lo haría la metafísica; por el contrario, sería una condición de la estructura en el juego de diferencias. El planteo de un juego diferencial en la estructura, como el de Derrida, se distancia de la tradición filosófica que prioriza la negación como determinación (omnis determinatio est negatio). Un pensamiento de la diferencia debe poder pensar algo y, al mismo tiempo, su negación constitutiva, a los efectos de determinar su diferencia, pero no puede caer en el argumento de que tal determinación sea un principio extra-estructural y fundamentador de la estructura/texto.

En consecuencia, una estructura descentralizada requiere de un complemento, de un elemento supletorio que pueda constituir esa carencia; a esto Derrida lo llama "suplementariedad". Al respecto, Frank es cuidadoso en su exposición. Indica que este concepto presenta dos particularidades. Por un lado, el suplemento es flotante, provisional y la interpretación añadida al texto "viene a ejercer una función vicaria... presenta de alguna manera una propuesta de cómo se podría sustituir el sentido central faltante del texto..."14. Por otro lado, esa añadidura frente a la falta no podría entenderse a modo de un encontrar. Si la interpretación añadida fuera un hallazgo, ello presupondría la presencia de un fundamento previo. Por el contrario, sería un inventar, un agregado de la interpretación provisional y flotante. De ese modo, Frank lo acerca a la crítica de arte romántica en la que la poesía es un oscilar permanente que no puede definirse. Friedrich Schlegel ha insistido en esta oscilación en el fragmento de Athenäum número 116, en el cual la poesía romántica tiene la posibilidad de: “... flotar, con las alas de la reflexión poética, ente lo representado y lo representante, quedándose suspendida entre ambos, libre de todo interés real e ideal, y elevar a la potencia una y otra vez esa reflexión, multiplicándola como una serie infinita de espejos... la poesía romántica, en cambio, se encuentra en devenir, y precisamente en esto consiste su verdadera esencia: en que solo puede devenir eternamente, nunca puede consumarse"15.

Tal oscilación del complemento como algo constitutivo, Frank la identifica tanto en la crítica inmanente que el romanticismo advierte en la obra de arte como en el modelo derridiano. La crítica como un elemento complementario de función vicaria no puede ser entendida como un agregado externo e intencional, de allí su flotar o autonomía en la crítica romántica. Frank lo expone

\footnotetext{
${ }^{14}$ Ibid., p. 80.

${ }^{15}$ Schlegel, F., Fragmentos, seguido de Sobre la incomprensibilidad, Barcelona: Marbot, 2009, p. 82 .
} 
del siguiente modo: "en el campo de la crítica artística lo reconocieron así ya los primeros románticos, que consideraban a la crítica literaria como complemento de una irreductible carencia en la obra de arte misma. Derrida está muy cerca de esta idea"16. Así, del mismo modo que la crítica romántica no puede definir un juicio determinante, optando por juzgar a la poesía poéticamente, la suplementariedad derridiana tampoco puede fijar un criterio desde el cual determinar la interpretación o el sentido. En el apartado cuatro ampliamos dicha relación mediante la comparación que realiza Frank entre la deconstrucción y el concepto de ironía romántica.

Luego de este análisis, que marca el camino desde el estructuralismo al neoestructuralsimo, Frank plantea tres preguntas que desarrollan la mayor parte del texto. Estas tres preguntas están referidas a la historia, la significación y la subjetividad. Si bien los tópicos de la historia y la significación pueden desarrollarse como intereses particulares, la discusión sobre la subjetividad y, por consiguiente, del concepto de modernidad, parece ser prioritaria y nodal para el autor. Por ello, nos detendremos en subrayar el problema de la subjetividad moderna en el neoestructuralismo que Frank pretende impugnar.

\section{El problema del sujeto en el neoestructuralismo: Nietzsche y el romanticismo}

A lo largo de las lecciones, Frank intenta impugnar el accord minimale entre estructuralismo y neoestructuralismo de que no existe un punto exacto, arquimédico, desde el cual interpretar el mundo. Apropiándose de la prioridad otorgada por la hermenéutica al sujeto y de los planteos sobre la autoconciencia de Henrich ${ }^{17}$, Frank demuestra que el ataque de los teóricos franceses al sujeto

\footnotetext{
16 Frank, M., ¿Qué es el neoestructuralismo?, p. 80.

17 No abordaremos aqui, más que referencialmente, los planteos de Dieter Henrich. Dicha tarea parece extremadamente compleja para los fines del trabajo. Solo nos limitamos a indicarlo como una de las fuentes e influencias que Frank desarrolla a lo largo de las lecciones, lo cual se constituye en una remisión ineludible para comprender su trabajo. En el caso de las lecciones, Frank retoma dos textos de Henrich (Kunst und Kunstphilosophie der Gegenwart. Überlegungen mit Rüscksicht auf Hegel, Immanente Äesthetik, ästhetische Reflexion, Múnich: Fink, 1966; "Selbstbewusstsein, kritische Einleitung in eine Theorie”, en: Bubner, R. y otros (eds.), Hermeneutik und Dialektik (Gadamer-Festschrift), Tübingen: Mohr, 1970, pp. 257-284) que le permiten apelar a su teoría de la subjetividad como una forma de saber de sí o autoconciencia. Contra el abandono de los deconstructivistas y buena parte de la filosofia contemporánea, Henrich (Vida consciente, Madrid: Síntesis, 2005) les recuerda que el sujeto es conciencia para sí, lo cual se conforma como un presupuesto originario e implícito que no puede hacerse pasar como un efecto secundario de una ficción, una estructura o las lógicas sociales. Pese a ello, nos parece que la complejidad de los planteamientos de Henrich que Frank recupera ameritan otro modo de abordaje. Naturalmente, Henrich tal vez sea uno de los autores contemporáneos ineludibles a la hora de pensar en la subjetividad, en particular porque el autor no sigue con los esquemas clásicos del conocimiento y
} 
autoconsciente prepara un enorme ejército en contra de un gran coro de hombres de paja ${ }^{18}$. El rechazo a los argumentos del neoestructuralismo contra el sujeto lo hará no sin antes rechazar a sus informantes alemanes: el antihumanismo de Heidegger, la crítica a la razón y la subjetividad de Nietzsche y la primacía del lenguaje en la elaboración psicoanalítica de Freud por medio de Lacan.

Según el análisis de Frank, la categoría de "sujeto" que el neoestructuralismo pretende impugnar no existe como tal. La reconstrucción del sujeto a partir de la crisis de la metafísica y de la representación elaboradas por Heidegger, Freud, Marx y Nietzsche, sumadas a la filosofia del lenguaje de Wittgenstein, Searle y Austin, serian para Frank un camino equivocado. Frank pareciera combatir el sentido común de fines de los años 80 y principios de la década del 90 sobre el fin de todo lo que se conoce como moderno. La politica de neologismos y prefijos que se colocan al lado de los conceptos elaborados en la modernidad parecen remitir a un aparato explicativo de la llegada de un nuevo momento histórico, o al decir de Frank, "el sobrio huésped del posmodernismo"19. Ya en su primera interrogación al neoestructuralismo (Lecciones 6 a 11), pone el acento en el concepto de historia derivado de Heidegger. En estas lecciones, se detiene en el análisis de la obra de Foucault y Althusser para indagar las variantes del concepto de historia. El punto de partida nuevamente son Fichte y Heidegger. Respecto del primero, Frank afirma que el neoestructuralismo depende de su imagen del ojo que nos ha sido inoculado. Del segundo, los neoestructuralistas asumen la determinación de que cuando "vemos algo como algo nos mantenemos ya en un claro (heideggeriano) del ser; que se desenvuelve en nosotros, pero no debido a nosotros" ${ }^{20}$. Ambas nociones pueden encontrarse tanto en las condiciones de posibilidad histórica de la episteme foucaultiana como de la ideología de Althusser. Lo que parece preocuparle a Frank en relación al concepto de discurso, producto de la articulación de diversos momentos históricos, es que esta noción daría cuenta de una formación discursiva que predetermina la voluntad del sujeto, lo que hace de él un títere de la historia. Así, pese a su atención en la historia, tanto la formación discursiva como la

emprende una tarea historiográfica como conceptual más compleja de las que se ofrecieron luego del cuestionamiento de la metafísica en la época poskantiana.

${ }^{18}$ Cf. Pippin, R., "On Not Being a Neo-Structuralist: Remarks on Manfred Frank and Romantic Subjectivity", en: Pippin, R., The Persistence of the Subjectivity, Nueva York: Cambridge University Press, 2005, pp. 168-185.

19 Frank, M., "Integración sin entusiasmo. La filosofia alemana entre la asimilación y el rechazo de la tradición”, en: Revista de Occidente. Pensar en alemán hoy, 282 (2004), p. 11.

${ }^{20}$ Frank, M., ¿Qué es el neoestructuralismo?, p. 111. 
estructura althusseriana muestran que la preocupación de Frank se concentra en el peligro de la inhabilitación del sujeto en su participación. Este sería un efecto de los cambios históricos y desplazamientos de las epistemes que se encuentran abiertas al juego infinito de las diferencias.

Ante estas consecuencias, Frank protesta mediante la recuperación de Saussure y exhibe la imposibilidad de abandonar cierta participación de la conciencia en la conformación de los significados históricos de las estructuras. Asimismo, el neoestructuralismo, en virtud de admitir fuerzas que el sujeto no domina, como la estructura, el campo, el discurso o la episteme que lo determinan, fracasa en su intento de crítica, pues su afirmación no se distancia de una reflexión en sí misma o inmanente como en Hegel. La figura de un campo discursivo que habla por el sujeto tal vez abandone la autoreflexividad asignada al sujeto, pero esta es transferida a la estructura o el discurso. De esa manera, la crítica del sujeto histórico queda eclipsada, según Frank, porque vuelve a una vieja figura de la filosofia clásica del sujeto ${ }^{21}$. Por ello, el autor sostiene: "la subjetividad reprimida en la posición del individuo retorna como la subjetividad de la estructura que reflexiona y se transforma actuando: retorno de lo reprimido"22.

A partir de estas consideraciones, Frank realiza una segunda pregunta centrada, específicamente, en la preocupación de la subjetividad. Su examen se concentra en Derrida y su análisis sobre los textos de Husserl, a los efectos de intentar derivar de ello una teoría de la conciencia y el sujeto. No obstante, su desarrollo previo se detiene en las fuentes que informan a los neoestructuralistas sobre el problema de la subjetividad: Nietzsche, Heidegger y Wittgenstein. En lo siguiente solo analizamos a Heidegger y a Nietzsche, donde Frank insiste sobre la imposibilidad de estructurar una historia de la subjetividad identificada con una modernidad que conduciría, necesariamente, a la identificación autoperceptiva del sujeto. El sujeto, a partir de estos autores, obtendría características como: ficción, inconsciente, dependiente, efecto, producto, etcétera. Todas estas nominaciones del sujeto indicarian el descentramiento del mismo, ya sea mediante un lenguaje privado que no gobierna soberanamente, la imposición

\footnotetext{
${ }^{21}$ Al respecto, Frank coloca cuatro críticas, de las cuales solo una reproducimos arriba; las otras tres son llamativas. Por ejemplo, en la segunda crítica encuentra un paralelo entre la explicación neoestructuralista de la conciencia y la aplicación de la teoría de la conciencia del monismo neutral de James, Mach y Russell, puesto que ambas consideraciones entienden al sujeto como un efecto secundario de relaciones del lenguaje estructural.

22 Frank, M., ¿Qué es el neoestructuralismo?, p. 117.
} 
de una estructura existencial de la que no puede dar cuenta, o bien por causa de una fuerza inconsciente que se le escapa.

Frente a estos postulados, Frank sostiene que existió en la tradición filosófica una superación de estos planteos que pretenden criticar los neoestructuralistas, a saber, los románticos alemanes ${ }^{23}$. Estos autores "no piensan ya la autoconciencia como una relación de reflexión... han descrito la autoconciencia de manera uniforme como carente del Yo y como temporal"24. El autor sostiene que frente a la concepción de la subjetividad neoestructuralista como algo ya puesto o instituido por el orden simbólico, existiría una excepción en la historia de la subjetividad que no se podria reducir a las descripciones heideggerianas de la subjetividad que asumen los pensadores franceses. Tal excepción la constituye el romanticismo, en la medida en que no puede analizarse como una reducción del sujeto al concepto de voluntad de poder. El romanticismo lograría pensar la autoconciencia como una relación de reflexión sin un yo que

${ }^{23}$ La propuesta de Frank parece consistir en advertir que en estos autores está cifrada la posibilidad de pensar a la subjetividad en términos no-reflexivos, algo que el neoestructuralismo parece verse impedido por seguir a Nietzsche y a Heidegger. El trabajo de Dieter Henrich le permite a Frank criticar la reconstrucción heideggeriana y post-estructuralista del pensamiento occidental como una “'Subjektivierung' des Seins”. En esa dirección, Frank intentaría mostrar, en primer lugar, que se trata de una distorsión del pensamiento filosófico durante los últimos doscientos años. Ni Schelling, ni Sartre, ni mucho menos los primeros románticos cuyas filosofias Frank menciona repetidamente como contra-ejemplos, habrian concebido la subjetividad en los términos simplistas de presencia e identidad como injustamente se los ha asociado. De hecho, Frank incluso sostiene que somos testigos en la época poskantiana de un giro contra nociones cartesianas y kantianas del sujeto. De las cuatro objeciones que Frank le realiza a Heidegger, la segunda objeción está dirigida contra su modo de interpretar el sujeto que se replicará también en el neoestructuralismo. Frank entiende al respecto que sería necesario desidentificar la noción de sujeto como la única determinación de la época moderna en tanto época de la reflexión. Heidegger al designar al sujeto como la característica esencial de la época moderna cree haber determinado al mismo mediante la reflexión de una autoconciencia que es presencia para sí, esto es, "estar para sí". Pero existiría evidencia en el romanticismo donde esta aplicación histórica de Heidegger no se podría aplicar. Los primeros románticos, Brentano, Schelling, etcétera, "rechazaron el modelo de reflexión del conocimiento como insuficiente precisamente cuando se tratará de describir la experiencia que tiene la conciencia de sí misma... si la experiencia de la autoconciencia fuera resultado de la autoreflexión, tendría que realizarse el siguiente proceso: el yo, todavía sin conocimiento de sí mismo, se vuelve representándose, hacia sí mismo, y se percibe ahí: a sí mismo. Pero, ¿cómo habría de percibir este hallazgo, si no hubiera tenido antes ya un concepto de sî?... más bien, tengo que haber tenido ya este hallazgo, y ponerlo en juego... si llego a obtener esta certeza, y con evidencia apodíctica, ella no puede ser el resultado de una reflexión, porque (como dice Novalis) 'Lo que encuentra la reflexión, parece ya estar ahí'... Si esto es así -y así es- entonces la autoconciencia tiene que ser explicada de manera distinta que a partir de la reflexión, es decir, como familiaridad consigo mismo que existe antes de cualquier reflexión, que es denominada desde Novalis como una autoconciencia que no se instaura a sí misma" (ibid., p. 221).

24 Ibid., p. 227. 
origina y controla todas las representaciones ${ }^{25}$. A juicio de Frank, el romanticismo temprano muestra que la fundamentación del yo se lleva a cabo desde un principio que no es él mismo, es decir, algo que no forma parte del sistema que lo asegura, pero que, al mismo tiempo, lo constituye. El autor sostiene que el romanticismo y Schelling evidencian el problema de la fundamentación del sujeto neoestructuralista: "Desde el principio, a los románticos y a Schelling la autoconciencia se les presentó como una relación que solamente se establece bajo la condición de una identidad fundamentadora, que se escapa del juego de las relaciones como tal. Por tanto, aquello que Lacan llamará assujettisation du sujet (desubjetivación del sujeto) no es un pensamiento nuevo, sino el retornar una idea especifica de la era moderna que se extiende continuamente desde Descartes y Spinoza pasando por Rousseau, Fichte, Schelling, Feuerbach, Kierkegaard y Schopenhauer, hasta llegar a Darwin, Nietzsche, Marx y Freud, todos los cuales fundamentan de común acuerdo, aunque con diversas acentuaciones, al sujeto autoconsciente en algo que no es consciente en sí mismo y de lo cual depende absolutamente (y que es fundamento interno, no externo)"26.

Frank considera que en la filosofia contemporánea se podría constatar un consenso al cual él mismo se adheriría: el sujeto no es ya un candidato que podemos elegir para la explicación de las cosas. No es un punto de partida (Descartes) ni un puerto de llegada (Hegel). Sin embargo, reconoce que el romanticismo permitió pensar a la individualidad como forma de romper el dominio universalista y mecánico, de forma tal que el sujeto no se transforme

\footnotetext{
${ }^{25}$ Frank (The Philosophical Foundations of Early German Romanticism, Nueva York: State University of New York Press, 2004) localiza los orígenes del primer romanticismo alemán en el giro copernicano kantiano, donde las teorias de la verdad como correspondencia dan paso a las teorías constructivistas de la verdad. Esto sugeriría que el sujeto constituye la estructura misma de la realidad a través de su actividad. Sin embargo, Frank argumenta que el romanticismo no debería interpretarse como una versión poética de Kant o el idealismo de Fichte, tal como había señalado la tradición crítica del romanticismo desde Hegel a Schmitt. Frank cree que lo característico del romanticismo sería su antifundacionalismo en relación a la verdad. El giro copernicano sería clave para el desarrollo del primer romanticismo alemán, en tanto sugiere que todo el conocimiento está sumido en un subjetivismo ineludible. Esto fue crucial para los románticos dado que reaccionaron en contra de este, tratando a ese gesto más allá del subjetivismo a través del arte. Sin embargo, lejos de glorificarse en su capacidad artística proyectiva, el intento de los románticos fue huir de ese subjetivismo, evidenciando tanto una "tendencia hacia el realismo" como cree Frank o bien, a lo que Elizabeth Millán Zaibert (Friedrich Schlegel and the Emergence of Romantic Philosophy, Albania: State University of New York Press, 2007), que sigue a Frank en sus consideraciones, ha llamado "humildad epistemológica". No desarrollamos otros conceptos de Frank en torno al romanticismo dado que excedería los limites de este trabajo, pero parece importante en algún momento establecer la conexión entre sus trabajos sobre el romanticismo y el neoestructuralismo. Dada la extensión y complejidad de la obra que estamos analizando, solo remitiremos al lector a los textos de Frank que anotamos en la bibliografia final.

${ }^{26}$ Frank, M., ¿Qué es el neoestructuralismo?, p. 220.
} 
en una reflexión cerrada en su propio autoconocimiento ${ }^{27}$. De este modo, Frank pretende mostrar que el error del neoestructuralismo sería confiar la historia de la subjetividad a la opinión de Heidegger, quien la reduce a una voluntad de apoderarse del mundo y de sí mismo ${ }^{28}$. El desconocimiento o falta de atención de Heidegger a la distinción romántica de una conciencia instauradora de una no instauradora conduce al neoestructuralismo a confundir autoconocimiento (autoconciencia) con autoreflexión. El reverso de la autoreflexión en los románticos no descansaría en un fundamento claro y distinto, sino "en algo que en sí mismo no es reflexionado" 29 . De ese modo, el neoestructuralismo desconoce, a causa de Heidegger, la teoría pre-reflexiva "de manera que, para él, el fenómeno de la subjetividad se reduce al totalmente distinto del autoconocimiento"30.

Frank indica, hasta el final de sus lecciones, de qué modo el objetivo del neoestructuralismo de quitarle la corona de rey de la filosofia al sujeto moderno no logra dar en el blanco. El enemigo creado por la filosofia francesa a partir de los maestros de la sospecha, en particular Nietzsche, no es más que una ficción elaborada por ella misma. Al igual que con Heidegger, Frank aborda las dificultades de la teoría de la subjetividad que los neoestructuralistas heredan de Nietzsche. El cuestionamiento del pensador alemán a la subjetividad como ficción de la interpretación sería retomada por el pensamiento francés, pero entendiéndola como una ficción del lenguaje. La lectura de Frank

\footnotetext{
${ }^{27}$ En Dios venidero (1994) y en Dios exilio (2004), Frank desarrolla con mayor detalle su apreciación sobre cómo la individualidad romántica elabora una forma de oposición al surgimiento del sujeto científico de la Ilustración. La individualidad rompe con la generalidad de la conciencia burguesa elaborada al calor del siglo de las luces, su particularidad no puede ser disuelta en la generalidad. En función de este análisis, Frank comprende que la individualidad romántica (dionisiaca) es indivisible y permite una unidad no mecánica. Alude a esto de la siguiente forma: "queda claro que lo individual no podría ser derivado de lo general. Ya Humboldt y Schleiermacher recalcaron que el aspecto individual e innovador de la utilización del lenguaje aparece en el habla poética como tal, mientras que en el habla científica aparece reprimido" (ibid., p. 402). Cabe aclarar que gran parte de las discusiones sobre el romanticismo que se establecen en esto textos están enmarcados en el llamado Mythos-Debatte. A raiz de esto no hemos incluido su análisis en el trabajo, pues nos conduciria a otros supuestos.

${ }^{28}$ Para Frank, Heidegger ignora la filosofia romántica y cae en un lugar común en su análisis en torno al romanticismo cuando lo ubica en la historia occidental de logos. La consideración de Frank supone pensar al romanticismo como una de las primeras críticas al subjetivismo y al fundacionalismo de la verdad, sin caer en una interpretación irracionalista o esteticista. Indica: "Es cierto (e incluso un lugar común de la filosofia romántica y de la idealista tardía) que la conciencia (incluyendo la autoconciencia) no es autora de sí misma, sino que se experimenta como lanzada, sin poder decirlo, en la determinación de ser un Yo. En esta medida no es dueña de sí misma. Presupone precisamente -además de su Ser desnudo- también una serie de oposiciones, sin las cuales no podría determinarse y comprenderse como aquello que es" (ibid., p. 313).

${ }^{29}$ Ibid., p. 226.

${ }^{30}$ Ibid.
} 
sobre Nietzsche y sus consideraciones sobre la subjetividad también parecen volver a impugnar esta fuente del neoestructuralismo mediante el argumento romántico de la subjetividad.

No obstante, habría que advertir que a Frank no le interesa Nietzsche en especial, sino sus derivaciones en la teoría neoestructuralista del sujeto. $\mathrm{El}$ autor observa que la valoración nietzscheana del sujeto podría entenderse bajo la figura de "un epifenómeno de la voluntad de poder o de la vida...", algo así como "un órgano de la falta de reconocimiento"31. El sujeto, comprendido como voluntad de verdad, no sería otra cosa que una elaboración secundaria de la voluntad de poder con el fin de mantener un estado social soportable, es decir, la invención de una ficción dependiente de un estado desconocido que se encuentra en pleno movimiento. En virtud de esta descripción de la subjetividad en Nietzsche, Frank cree que los neoestructuralistas harian descansar su teoría del sujeto en una inversión que debe entenderse solamente como proyección aparente de algo que se encuentra más allá de las propias posibilidades del sujeto. Esto conduciria, entonces, a detectar en Nietzsche un "partidario de un cierto subjetivismo... aunque no de un subjetivismo idealista sino de uno voluntarista, de manera tal que la voluntad de poder que produce las representaciones y los valores, es precisamente el sujeto verdadero"32.

De ese modo, en el análisis de Frank, Nietzsche y el neoestructuralismo parecerian caer en una contradicción al distinguir entre un sujeto verdadero (voluntad de poder) y uno falso (proyección, ficción, ilusión necesaria). En primer lugar, esta distinción desmentiría la premisa de "la apertura e infinitud de las interpretaciones y la imposibilidad de fijar gramaticalmente al sujeto, que solo es verdadero en el devenir, es decir, el sujeto de la voluntad"33. En segundo lugar, el argumento de Nietzsche en la distinción antes indicada olvidaría la "concepción romántica y humboldtiana del lenguaje, que era dialéctica y había concebido el proceso de transmisión del lenguaje como relación de efectos recíprocos entre lo general y lo individual" 34 . La pretensión de Frank parece conducirse a mostrar de qué modo Nietzsche y los neoestructuralistas reducen al sujeto a un mero efecto del lenguaje. En esa dirección, la teoría neoestructuralista sustituiría al sujeto trascendental por "un efecto del esquematismo lingüístico"35. Apelar

\footnotetext{
Ibid., p. 229.

Ibid., p. 235.

Ibid., p. 239.

34 Ibid.

35 Ibid., p. 235.
}

ARETÉ Revista de Filosofía, vol. XXXI, N 1, 2019 / ISSN 1016-913X 
exclusivamente a la filosofia del lenguaje para interpretar la noción de sujeto le parece a Frank una reducción a los efectos del lenguaje. A propósito, indica que Nietzsche representa para el pensamiento francés un cambio de la interpretación del sujeto trascendental en el sentido de una filosofia del lenguaje. Frank sostiene: “...la teoría del sujeto de Nietzsche pone en juego todavía otras cosas, más que la idea del desconocimiento necesario: en primer lugar, la idea de que el sujeto, debido a su inaprehensibilidad, no puede ser subsumido bajo ningún concepto, tampoco bajo ningún concepto científico (él comparte, como variable semántica, la indeterminación de todo lo semántico, y permite 'interpretaciones infinitas'); pero en segundo lugar, la fundamentación en la filosofia del lenguaje de la teoría del sujeto, tan característica del neoestructuralismo. De acuerdo con ella, la autoconciencia no depende simplemente del 'sujeto verdadero', del inconsciente, más bien resulta ser un efecto del lenguaje, o, como lo dice Lacan, del significante"36.

Si bien las últimas tres lecciones están destinadas a analizar la teoría de la significación del neoestructuralismo, en especial las críticas de Derrida a Husserl y el pragmatismo de Searle y Austin, el problema de la subjetividad no desaparece. Frank entiende que Derrida, Foucault y Deleuze no disponen de las armas necesarias para ese ataque, en gran medida por su desconocimiento de las teorías de la autoconciencia romántica. Básicamente, contar la historia de la subjetividad como un desarrollo de interpretaciones sobre el Ser como presencia (al modo heideggeriano) hasta llegar al oscurecimiento u olvido del mismo en la autoconciencia como presencia ante sí de la era moderna, constituye una falacia, además de ser "demasiado bella para ser verdad" ${ }^{37}$. De este modo, sería inexacto, por caso, que el romanticismo piense a la autoconciencia como presencia ante sí. La teoría romántica parte del escepticismo de una instancia segura para el Yo. Dicho fundamento no es inmediato ni tampoco presente, de modo tal que hace imposible un sistema del saber autoconsciente. Frank asevera que "les debemos la clara comprensión de la imposibilidad de pensar la familiaridad que la conciencia tiene consigo misma como una relación de reflexión... son de una calidad de la que no cae ni un reflejo sobre la obra de Derrida"38. La filosofia romántica ha postulado desde Novalis a Schlegel que la conciencia no es productora de sí, expropiándole el derecho de autonomía y soberanía atribuida por el neoestructuralismo. Incluso, si pensamos en autores

\footnotetext{
36 Ibid.

37 Ibid., p. 289.

38 Ibid., p. 290.
} 
como Schelling, se utilizan conceptos como "Ser Inmemorial" para distinguir aquello que la conciencia no dispone. A partir de esto, la conciencia se mostraría lanzada y desnuda, sin tener el poder de determinarse a sí misma.

\section{Estética romántica, subjetividad y neoestructuralismo}

En su análisis, pese a no estar convencido del reconocimiento del sujeto como agente natural de la razón universal, Frank no descuida aspectos que podrían ser destacados en las obras neoestructuralistas. En este sentido, parece necesario prestar especial atención a la forma en que estudia a Derrida ${ }^{39}$. En varios pasajes reitera que en última instancia Derrida no estaría dispuesto a suprimir definitivamente la autoconciencia, sino a explicarla por otros medios, es decir, medios no metafísicos. En este caso, su explicación trata de poner en relación la obra derridiana con algunos tópicos románticos para advertir sus similitudes. Sin embargo, en esta oportunidad, su valoración parece centrarse en destacar los alcances positivos del neoestructuralismo en Derrida.

Inicialmente, la posición hermenéutica de Frank no aparenta renunciar a que todo sentido, significante, significado o interpretación, se refiera o esté sugerida a una conciencia. Su explicación del neoestructuralismo convoca a defender la conciencia que otorga sentido, es decir, a confiar en "que puede defender exitosamente su realidad del intento neoestructuralista de disolverla (o más bien: desaparecerla) en el hueco de la différance"40. Frank sostiene que la explicación de la autoconciencia que Derrida ofrece como "un efecto de relaciones diferenciales entre las marcas de una 'estructura' a la que se ha privado de límites"41, no supone la relación de familiaridad de la conciencia consigo misma ${ }^{42}$. Frente a este planteo, el autor alemán cree que la noción de Selbstbewusstsein de Henrich permite explicar mejor el concepto de auto-

\footnotetext{
${ }^{39}$ Al respecto, un estudio dedicado y profundo, puede encontrarse en Hauge, H., "The Will to Consensus: Manfred Frank on Derrida”, en: MLN, v. CV, 3 (1990), pp. 596-609.

${ }^{40}$ Frank, M., ¿Qué es el neoestructuralismo?, p. 315.

41 Ibid., p. 311.

42 En esta dirección afirma: "Contra Derrida, yo objetaría que, si se quisiera dar consistencia a su idea, tendría que llegar al absurdo de refutar la existencia de algo así como la familiaridad con nosotros mismos. Pero esto no solamente estaría en contradicción con lo que él mismo menciona como su intención (es decir, simplemente la de querer explicar la autoconciencia de otra manera que en la metafísica); también desembocaría en la negación del hecho de que podemos vincular un significado, en términos generales, con las expresiones 'mismo', 'conciencia', y 'Yo', en nuestro lenguaje cotidiano. Esto es una contradicción con el funcionamiento mismo del lenguaje" (ibid., p. 310).
} 
conciencia. Tal noción, supone Frank, evita la explicación de la relación de la conciencia con un "ser otro" no familiarizado con la propia conciencia.

Sin embargo, debe reconocerse que en el apéndice final dedicado a Derrida, la perspectiva sobre el pensador francés no adquiere la valoración peyorativa que se podría desprender del conjunto de las lecciones. En este apéndice, Frank se concentra en el texto La diseminación, cuya escritura y planteamientos cargaria con la herencia del simbolismo de Mallarmé. A través del simbolismo de dicho poeta, Frank identificará la cercanía de Derrida a la ironía romántica de Schlegel. La deconstrucción a los ojos de Frank no podría reducirse a destrucción, pues "los textos leídos, como las construcciones de sentido que son, tienen que ser demolidos hasta sus cimientos, para poder revelar su plano de construcción; pero después deben ser reconstruidos de nuevo y de otra manera"43. Por medio de esta definición, Frank destaca la doble marca que se presenta en el análisis de Derrida sobre Mallarmé. Las apelaciones de Derrida a Mallarmé buscarian ese grado suplementario en el cual existe la posibilidad de identificar un "momento" reflexivo que no se resigna a la destrucción total del sentido. Esa añadidura o exceso a la totalidad de sentido no busca afirmarse como una oscuridad o absurdo, sino a modo de una inscripción necesaria de todo texto que, en beneficio de sí misma, se ausenta. Dicho descubrimiento, por parte de Derrida a través de la écriture de Mallarmé, no es otra cosa que la ironía romántica.

Aquello que en la tradición de la estética romántica alemana de Schlegel y Tieck se llamaba ironía romántica "no es muy distinto del procedimiento que Derrida descubre en la écriture de Mallarmé"44. Ambas revelan un doble código, como diría Paul de Man en su conferencia "El concepto de ironía"45, el cual no permite que los sentidos se cierren en sentido último o final, pues dicha estructura siempre muestra un faltante, un vacío o intersticio que se desplaza. En palabras de Frank, la ironía romántica sería: “...la negación de un sentido determinado y unívoco a favor de una retroreferencia a las condiciones de posibilidad bajo las cuales se vuelve posible en realidad un habla ambigua semejante. Novalis y Schlegel llamaban a esto 'poesía trascendental', de modo semejante a Mallarmé, que hablaba de 'poesía reflexiva', y llamaba a esto la 'crisis de la literatura', aquel momento, 'cuando nada tiene lugar más que el lugar, en la instancia en que nadie está ahí para saberlo... La duplicación del

43 Ibid., p. 493.

44 Ibid., p. 503.

45 Cf. De Man, P., La ideología estética, Madrid: Cátedra, 1998, p. 239. 
signo, en cierto modo reflexiva... evita que la cadena semántica se cierre sobre un último sentido final o cardinal, cuyos significados parciales se pudieran categorizar"46.

También la perspectiva de Frank en torno a Derrida plantea un reconocimiento de la tradición idealista en su versión fichteana. A juicio de Frank, la paradoja de la autoconciencia de Fichte, según la cual esta lleva en sí la huella misma de su determinación pero, a su vez, ella es distinta de lo existente, no sería otra cosa muy distinta de lo designado por Derrida como diferancia. El pensador alemán cree que el posestructuralismo no puede ser otra cosa que "variaciones de la fórmula de Fichte de la mirada introducida, o del ojo insertado; una formula, por tanto, que quiere expresar con imágenes que la mirada con la cual tenemos acceso a nuestro mundo no ha sido creada por nosotros, sino que nos ha sido implantada... que nos ha sido inoculada"47.

En definitiva, lo que le preocupa a Frank de fondo, además de lograr establecer la relación entre posestructuralismo y romanticismo, parece ser la impugnación de un modelo de subjetividad que aparentemente identificaría la conciencia consigo misma. La interpretación neoestructuralista del sujeto supone, según Frank, "a la autoconciencia como un caso de reflexión: es decir, como la relación explícita de una conciencia consigo como su propio objeto"48. A contrapelo, acentúa, bajo el modelo de la autoconciencia de Henrich, que la autoconciencia al no renunciar a la familiaridad consigo misma no podría interpretarse como una autoidentificación. Explica este proceso del siguiente modo: “...el sujeto nunca coincide absolutamente con su Ser... pero claramente tiene conciencia de sí como un proyecto que no coincide consigo mismo... En este sentido sería totalmente equivocado decir... que en el caso de la autoconciencia se trata de la acción de una identificación. El Yo familiarizado consigo no realiza una autoidentificación, él está familiarizado consigo desde antes que se proyecte hacia los contenidos en cuyo lugar él interpreta su propio Ser... 'La familiaridad de la conciencia consigo misma', escribe Dieter Henrich, 'no puede ser entendida en absoluto como el resultado de una empresa'... ni como 'efecto' de relaciones diferenciales entre marcas, ni como efecto del acto de una identificación: la conciencia siempre existe de antemano... En pocas palabras:

\footnotetext{
${ }^{46}$ Frank, M., ¿Qué es el neoestructuralismo?, p. 503.

47 Ibid., p. 111.

48 Ibid., p. 317.
} 
la autoconciencia no es un fenómeno al cual pudieran aplicarse con sentido las categorias de la identidad o de la diferencia"49.

Pese a esta impugnación de la teoría del sujeto neoestructuralista y sus fuentes, Frank produce una ambivalente recepción de esta tendencia. Por un lado, coloca en discusión los puntos cardinales de la filosofia francesa valorando algunas de sus indicaciones ${ }^{50}$; por otro, se pueden observar indagaciones críticas que producirán cierta recepción menos reactiva de la que se puede encontrar en los escritos de Jürgen Habermas por la misma época.

A primera vista, estas lecciones pueden ser un intento de diálogo fecundo entre dos tradiciones filosóficas que durante una parte del siglo XX permanecieron aisladas. Si a principios de los años 80 la Teoría Crítica, de orientación hegeliano-marxista, y la Teoría de la acción comunicativa, orientada por Habermas, ya no encontraban el horizonte y la autoridad que tuvieron en años pasados, el respiro parecería traerlo los aires convulsionados de la Francia postmayo del 68 en los nombres de Foucault, Derrida, Deleuze y Lacan. La oposición alemana encabezada principalmente por Habermas a estas tendencias no tuvo el fruto esperado ${ }^{51}$. Así, se abrió la posibilidad tanto para la lectura de estos

\footnotetext{
${ }^{49}$ Ibid.

${ }^{50}$ En la reseña antes indicada de Holub, el autor no duda en calificar a Frank como un postestructuralista. Señala Holub: "A pesar de sus dudas filosóficas y políticas, Frank debe ser considerado un defensor en lugar de un opositor al posestructuralismo. De hecho, el atractivo de su posición es que demuestra que se puede apreciar, apropiar y aplaudir una variedad de posiciones postestructuralistas y puntos de vista sin renunciar a una perspectiva crítica" ("Review: Was is Neostructuralism?", o.c., p. 116). Esta indicación tal vez no sea del todo justa, pero servirá para ubicar a Frank dentro del ámbito teórico americano. De hecho, en la recepción de su trabajo sobre el romanticismo, Frank aparecerá en las dos versiones sobre el romanticismo, ya sea como un intérprete que supone al romanticismo como deconstrucción avant la lettre, o bien como un autor que pretende evitar la reducción de romanticismo a posmodernismo. Para lo primero, puede verse el trabajo de Beiser (The Romantic Imperative: The Concept of Early German Romanticism, Cambridge: Harvard University Press, 2003); para la segunda consideración, puede verse Frank (The Philosophical Foundations of Early German Romanticism, 2004) y Elizabeth Millán-Zaibert (Friedrich Schlegel and the Emergence of Romantic Philosophy, o.c.).

${ }^{51}$ Antes de la recepción y discusión que Habermas realiza en plena confrontación con el posestructuralismo en El discurso filosófico de la modernidad, las lecciones de Frank parecen un intento de lectura crítica de estas corrientes desde la hermenéutica. El autor parece evidenciar que su texto tiene como propósito establecer un diálogo de aprendizaje con las corrientes francesas, pero sus derivaciones encontraron más resistencias de las que imaginó. Por ello, su posición podría ser considerada ambigua y paradójica respecto al neoestructuralismo. En Francia, las lecciones sobre el neoestructuralismo ayudaron a aumentar el rechazo a la filosofia alemana $\mathrm{y}$, en Alemania, por su parte, permitieron despertar el interés en el estudio de estas corrientes, como también, su rechazo. Al respecto, pueden verse las discusiones en un dossier preparado por Gérard Raulet ("Le siège de la Raison ou une philosophie entre plusieurs chaises. Bilan de la philosophie allemande actuelle", en: Allemagnes d'aujourd'hui, 99/100 (1987)). En este número de la revista, diversos intelectuales de Francia y Alemania discuten acerca de las posibilidades y consecuencias del debate franco-alemán en filosofia.
} 
filósofos, como la posibilidad de pensar los nuevos procesos socio-politicos en Alemania sin la tutela del paradigma de la Teoría Crítica ni Habermas ${ }^{52}$.

\section{A modo de cierre: el debate franco-alemán y la tradición estética}

En un texto traducido con el nombre de "Integración sin entusiasmo", Frank muestra la ambivalente relación (rechazo y asimilación) que la filosofia alemana establece con la filosofia francesa. En este escrito sostiene que la filosofia debe enfrentarse a dos tareas: "abrir la puerta a la esperanza y gestionar la resignación" 53 . Esa doble tarea que la filosofia asumiría sería la que enfrenta Alemania en los años 80 con la nueva filosofia francesa. Para Frank, el ingreso de la filosofia francesa encuentra un contexto desfavorable para su recepción, pues ni las ciencias ni la filosofia encontraban en ese momento respuestas a la "crisis de sentido". En virtud de ese marco, reconoce que la "...única filosofia que estaba disponible dentro de la inquebrantable tradición era la entonces genéricamente denominada filosofia existencial, y en primer lugar la desnazificada ontología fundamental de Martin Heidegger, cuya aversión tanto hacia el 'racionalismo occidental' de los analíticos del lenguaje como hacia el neomar-

\footnotetext{
52 Gerard Raulet describe esta situación del siguiente modo: "Las lecciones pronunciadas en Dusseldorf y Ginebra por Manfred Frank y publicadas con el titulo Was ist Neo-Strukturalismus? en 1983 tuvieron mucho que ver con ello. Iniciaron a toda una generación de jóvenes filósofos de habla alemana en los nuevos enfoques franceses. La fuerza innovadora de los autores franceses arremetió contra una Teoría Crítica que, en la persona de Jürgen Habermas, se renovaba ciertamente de manera inexorable pero lenta. Invitado al College de France en 1983, este último adoptó como estrategia una ofensiva frontal contra las corrientes francesas; ya en 1980, cuando recibió el Premio Adorno de la ciudad de Fráncfort, había mostrado sus cartas en 'La modernidad, un proyecto inacabado', al calificar de neoconservadurismo 'la tendencia que va de Georges Bataille a Derrida, pasando por Foucault'... Esta (contra) ofensiva se publicó en alemán en 1985 con el título El discurso filosófico de la modernidad; tuvo como resultado que se abrieran las compuertas para recibir al posestructuralismo y al pensamiento postmoderno en Alemania. Manfred Frank tiene no solo el inmenso mérito de presentar, en forma de lecciones universitarias aparentemente neutras, las corrientes incriminadas, sino también de comprometerse para entablar un diálogo de base con los pensadores franceses; con ello contribuyó, sin compartir por ello el entusiasmo de los pequeños editores que se pusieron a publicar todo lo que venía de Francia, a afianzar la referencia al posestructuralismo francés en los debates filosóficos alemanes. Desde entonces, paralelamente a los pequeños editores como Merve, los grandes, principalmente Suhrkamp, incluyeron, a los filósofos franceses entre los valores seguros de sus programas. Hubo más textos de Derrida, Foucault, Lyotard, Baudrillard, etcétera, traducidos al alemán que, en un primer momento, de Habermas y la Teoría Crítica en su conjunto traducido al francés. Un efecto de esta coyuntura franco-alemana es que, por el lado francés, Foucault admitió, en una entrevista que dio la vuelta al mundo, que sus posiciones no eran en nada incompatibles con las de la Escuela de Fráncfort, al menos con el diagnóstico de la autodestrucción de la Razón formulado en Dialéctica de la Ilustración (1944)" (Raulet, G., La filosofía alemana después de 1945, Valencia: Universidad de Valencia, 2009, pp. 289-290).

${ }^{53}$ Frank, M., ¿Qué es el neoestructuralismo?, p. 7.
} 
xismo de la Escuela de Fráncfort supuso un pesado lastre para el despegue de la filosofia de la posguerra en Alemania"54.

Luego de esta descripción, el autor alemán indica que, con la llegada de la década del 80 , la crisis del sentido se agudizó en distintos puntos intelectuales llevando a la desilusión, la desesperanza y la sospecha sobre los valores heredados por la modernidad. Todo aquello que era claro y distinto, racional y ordenado comenzó a ser reemplazado por una nueva norma: "la falta de claridad". Frank cree que tal norma dio lugar al posmodernismo o neoestructuralismo como un nuevo pathos intelectual en distintas disciplinas desde la literatura hasta las ciencias sociales pasando por la politica. La emergencia de esta nueva situación intelectual presiona sobre la filosofia alemana y la obliga a llevar a cabo un tipo de integración de dicha situación novedosa. Sin embargo, esa integración se encuentra atravesada, por una parte, por la agonía de la pérdida y, por otra, por la resistencia a la vuelta de sus propias raíces que la filosofia alemana quiere negar ${ }^{55}$.

El logocentrismo y la crítica a la metafisica alemana (Nietzsche-Heidegger) se fueron a Francia para encontrar un mejor lugar. El racionalismo y la claridad marcharon a los esfuerzos intelectuales alemanes para sortear las dificultades irracionales del pasado. Dicho de este modo, Frank puede reconocer el retorno de lo reprimido del mundo filosófico alemán. Esa inversión, conjetura Frank, habría producido un descenso en la confianza de unos y otros, llevando a muchos al rechazo. Volviendo a la explicación de Frank de la relación entre Francia y Alemania en la filosofia, podríamos hacer notar que el punto de discordia más fuerte entre ambas esferas intelectuales puede residir en la lectura e interpretación que cada una lleva a cabo de lo que entendemos por tradición filosófica. Afirma al respecto: "En Francia se ignora, en buena medida, lo que ocurre en la filosofia alemana contemporánea (están tremendamente ocupados con la filosofia alemana antigua); y en Alemania hay dos tendencias predominantes, ambas igual de estériles. Una es la imitación puramente mecánica e incondicional, un sometimiento al nuevo pensamiento francés que raya el altruismo

\footnotetext{
54 Ibid.

55 Frank sostiene que: "En su enorme esfuerzo de integración la filosofia alemana había eludido claramente algo que ahora penetra en sus instituciones con la violencia de lo reprimido y causa daños (molesta) en sus escuelas: la sospechosa metafisica (crítica) alemana, calumniada y desacreditada por irracional, invadió la filosofia de nuestros vecinos franceses tras la caída del existencialismo marxista y en ese país se mostró resistente frente a la ética del análisis y de la búsqueda de sentido hermenéutico, y frente a la ética en general. De allí vuelve hasta nosotros como la cara oculta (y rechazada) de nuestra propia cultura filosófica. Y, como tal, supone adquisición de conocimiento y ofrece la oportunidad de una introspección renovada" (ibid., p. 11).
} 
místico. La otra es la polémica, por lo general más subida de tono cuanto menos informada está, sobre las tesis del enemigo de la fantasía. Ambas reacciones permiten considerar el trauma como una motivación. Mientras alli se busca la adhesión incondicional a la deteriorada tradición, aqui en cambio prefieren desprenderse de ella a toda costa"56.

Frank afirma que esa polaridad de rechazo e integración "solo puede presentarse como subordinación a quien deja que esta prehistoria de la crítica a la modernidad y al logocentrismo se evapore de sus estudios en lugar de verificarla en las fuentes" 57 . Esto no quiere decir que vaya a existir una especie de demarcación entre una lectura correcta e incorrecta de la tradición moderna. Antes bien, pretende advertir sobre cómo las reelaboraciones conceptuales de la tradición filosófica moderna pueden llegar a conclusiones estrepitosas si no indagamos en sus fuentes. Pese a ello, Frank en ese breve texto parece ser mucho más desafiante de lo que declaraba en sus lecciones sobre el neoestructuralismo y su llamado al diálogo franco-alemán.

Así, las lecciones sobre el neoestructuralismo parecen estar distantes de las posiciones que asume el autor en los dos textos antes referidos. Este texto parece estar más cerca de las opiniones de Frank elaboradas en su La piedra de toque de la individualidad (1995). Haciendo referencia a las alternativas de la filosofia alemana en relación a la filosofia francesa, vuelve a señalar al pensamiento francés con una calificación un tanto despectiva como los "amigos de lo absurdo". Indica: "En nombre de una deconstrucción del espíritu está teniendo lugar una cobarde represión de la responsabilidad moral y cognitiva similar al menos a la que, en nombre de la razón y la libertad, se ejerce en el oscuro (por no decir absurdo) fundamento de la racionalidad. Da la impresión de que la filosofia alemana no se liberará de esta alternativa tan poco dialéctica hasta que reconozca en la provocación postmoderna -francesa, sobre todo- la oportunidad de reencontrarse con su verdadera y renegada tradición. Deberá, desde luego, trabajar sin descanso en un nuevo lenguaje más luminoso que el galimatías que han introducido los amigos del absurdo"58, lo cual muestra una lectura peculiar ${ }^{59}$.

\footnotetext{
56 Ibid., p. 12.

57 Ibid.

58 Ibid., p. 14.

59 Según Martin Schwab ("Foreword”, en: Frank, M., What is Neoestruturalim? Mineápolis: University of Minnesota Press, 1989, pp. X-XLIV) la lectura de Frank respecto a esta relación se podría inscribir en una reacción racionalista hermenéutica frente al irracionalismo deconstructivista proveniente de Francia. Para Schwab este debate nos permite observar la polaridad entre racio-
} 
En este sentido, parecería más apropiado inscribir esas declaraciones en la línea del Habermas de "La modernidad, un proyecto inacabado" (1985) sobre la filosofia francesa. En este contexto de hostilidad hacia el posestructuralismo, la posición de Frank en las lecciones adquiere una particular relevancia a los fines de entender en profundidad la recepción alemana de la filosofia francesa. Asimismo, permite reconstruir algunas críticas al posestructuralismo sin caer en lugares comunes y segregacionistas, como también evita la aceptación celebratoria que llevó, en algunos ámbitos intelectuales, a convertirlo en un dogma. De hecho, a pesar de tales críticas, la recepción en el ámbito alemán no pudo ser frenada por el pesimismo de algunos intelectuales alemanes.

Robert Holub ${ }^{60}$ destaca que los libros de los pensadores franceses, aunque comenzaron a circular en alemán, no tuvieron la aceptación complaciente y celebratoria que sí obtuvieron en Estados Unidos. Holub identifica tres razones por las cuales el pensamiento francés no logró los resultados que tuvo en Norteamérica. La primera es que no pudo formarse inmediatamente algo así como una "escuela de Yale" alemana, aunque este concepto de "escuela" sea cuestionable. Al no encontrar referentes intelectuales en los circuitos académicos, el pensamiento francés no se constituyó como un núcleo de pensamiento. La segunda razón se debe a la falta de puestos de trabajo en las universidades alemanas en esa época, a diferencia de los Estados Unidos,

nalismo e irracionalismo en la medida en que se esté poniendo en juego la presencia determinante del sujeto en la interpretación o la desaparición definitiva del mismo a manos de fuerzas que lo superan. El mapa donde Schwab sitúa la obra puede ser útil para extraer las consecuencias de las lecciones de Frank, pero no para entender las razones que este tiene para sostener su lectura. La afirmación de este autor con respecto a entender las lecciones de Frank como una reacción racionalista frente al avance irracionalista de la deconstrucción corre el peligro de reducir la lectura de la obra a un mero epifenómeno de la polaridad de estas corrientes, alejándose de las interrogantes, críticas, coincidencias y confrontaciones con el neoestructuralismo. Su consideración coincide con posturas como las de Christa y Peter Bürger (La desaparición del sujeto, Akal, Madrid, 2001), quienes apoyan está versión de la desaparición del sujeto en el plano de la literatura. Su rastreo va desde Montaigne hasta Blanchot, y sostienen que existen dos modos de ver al sujeto, uno vinculado a Lyotard y el posmodernismo, y el otro relacionado a Manfred Frank y la afirmación del sujeto. En nuestro caso, preferimos optar por el análisis que realiza Maurizio Ferraris. Este autor, sostiene que la intención de Frank sería inscribir al posestructuralismo 100 dentro de la tradición hermenéutica alemana. De ese modo, el pensamiento francés ayudaria "a superar los vínculos de la tradición romántica de las ciencias del espíritu y, por otra parte, ésta suministraria un repertorio de soluciones y de tipologias capaz de enriquecer el ámbito de referencia y el canon filosófico (relativamente restringido) en el cual se avala el desconstruccionismo" (Ferraris, M., Historia de la hermenéutica, México D.F.: Siglo XXI, 2005, p. 292).

${ }^{60} \mathrm{Si}$ bien la intención de Holub es determinar de qué modo el posestructuralismo llegó a politizarse dentro de contextos poco propicios tanto en Alemania como en EE.UU. (fue identificado como posmodernismo, pro-capitalista, conservador, reaccionario, nihilista y otras acusaciones más), tomamos su reconstrucción histórica para dar cuenta de la aparición de cierta recepción favorable en Alemania. 
donde ser posestructuralista no parecía ser un inconveniente para acceder a los puestos universitarios. Por último, Holub afirma que si en los Estados Unidos el posestructuralismo tuvo niveles de celebridad hollywoodense por haber venido a ocupar un espacio de crítica, esto no sucedió en Alemania, pues dicho espacio no existía. Según Holub, la crítica politizada alemana no tenía contacto con el pensamiento francés al punto de ser escasa su recepción tanto en la izquierda como en la derecha conservadora.

Las apelaciones a Nietzsche y Heidegger por parte de los posestructuralistas todavía tienen un sabor amargo por esos años en Alemania y pueden habilitar a una tendencia conservadora. Sin embargo, Holub indica que a pesar de que el posestructuralismo no consigue afianzarse, sí logra despertar intereses en la crítica contemporánea alemana. Existiría un grupo de pensadores alemanes de formación dispar, provenientes de distintas tradiciones teóricas y filiación ideológica diversa, que se podrían agrupar por su preocupación en la filosofia francesa como "posestructuralismo alemán". Este grupo heterogéneo de autores no tiene un líder espiritual, un referente natural, ni una universidad alemana de residencia y ni siquiera un lugar estable de trabajo donde situarlos. Estaría compuesto por: Norbert Bolz, el propio Frank, Werner Hamacher, Jochen Horisch y Friedrich Kittler. Pese a que sus nombres permanecian bastante desconocidos en los años 80, Holub observa que sus publicaciones en la dirección posestructuralista ya vienen de la década del 70. Aunque puede parecer antojadizo hablar de "posestructuralismo alemán", existiría cierto trasfondo común entre muchos de los representantes que Holub distingue bajo tal clasificación. En su mayoría estos autores parecen hablar de literatura y de filosofia como si explicaran lo mismo. Casi todos tienen como punto de partida o, al menos, como referencia obligada autores de la "época de Goethe" y los románticos alemanes. Además, sus análisis de estos temas parecen apelar a tomar un tema "literario" para desde ese lugar emprender una reflexión teórica, en la cual la retórica les permite jugar con los objetos que abordan. Nietzsche, Freud, Derrida, Foucault y Lacan parecen ser la lente desde donde miran el lenguaje y casi todo en general, a los efectos de desentrañar el peligro de la metafísica que se oculta si no deconstruimos su representación.

Gérard Raulet, por ejemplo, explica que la situación en los años 80 cambió radicalmente, e incluso con todos los esfuerzos por contrarrestar el impulso francés, estas voces fueron escuchadas en Alemania. Una clave interesante de remarcar para este diálogo franco-alemán, siguiendo a Raulet, es el reconocimiento de ciertos puntos de contacto entre el redescubrimiento de Dialéctica de 
la Mlustración y los planteos de Foucault en su crítica a la razón autodestructiva. De algún modo, y a diferencia de la hipótesis de Holub, quien entiende que la politización del pensamiento francés en Alemania fue un obstáculo para su recepción, Raulet sostiene que el posestructuralismo vino a "inspirar" la posibilidad de actualizar la Teoría Crítica ${ }^{61}$. Sin entrar en demasiados detalles, los trabajos de Christoph Menke también parecen ser un intento de actualización dentro de la Teoría Crítica a partir del cruce entre la estética alemana de corte adorniano y la deconstrucción. De hecho, Soberanía del arte (1997) examina en la segunda parte de su trabajo el origen estético de la deconstrucción siguiendo las orientaciones de ¿Qué es el neoestructuralismo? de Frank ${ }^{62}$.

En esa dirección, los desacuerdos en el debate franco-alemán parecen ser menos controvertidos si seguimos la tradición estética. Andrew Bowie ha remarcado que a partir de la fuerza de la estética de Adorno se podria hallar un "intento de combinar estos dos enfoques contradictorios, lo que apunta a una posible reconciliación de algunas de las siguientes oposiciones, que han establecido los términos de este debate franco-alemán"63. En esa línea, nombres como los de Karl Bohrer, Werner Hamacher, Peter Szondi y Wolfgang Welsch permiten establecer algunos puntos de contacto más receptivos que la polaridad entre rechazo e integración planteada inicialmente en el debate francoalemán. La aceptación de muchos teóricos de los años 80 y 90 de aceptar la oposición entre Modernidad vs. Postmodernidad favoreció los reduccionismos, como la limitación de los planteos que se ponian en discusión (Teoría Crítica alemana, Posestructuralismo francés y la teoría artística norteamericana). En su lectura del debate franco-alemán, Bowie nos posibilita observar de qué forma el legado de la modernidad puede continuar siendo discutido sin apelar a un corte definitivo con ella. Tanto el debate franco-alemán como las obras de los distintos pensadores que hemos situado en esta última parte parecen habilitar una extensión de las posibles lecturas de lo que entendemos por modernidad

${ }^{61}$ Raulet comenta que en "1977, Wolfgang Bonss y Axel Honneth... adoptaban una línea de argumentación defensiva respecto al 'post-estructuralismo' al señalar 'la similitud inesperada 102 entre la Dialektik der Aufklarung y el post-estructuralismo francés, de Foucault hasta Baudrillard'. La actualidad de la Dialéctica de la Ilustración y de la Kritik der instrumentellen Vernunft de Horkheimer (Eclipse of Reason, traducido al alemán en 1967) era el resultado, según ellos, de un escepticismo generalizado hacia la ciencia 'que la crisis del marxismo disimulaba al radicalizarlo"' (Raulet, G., La filosofia alemana después de 1945, p. 291).

${ }_{62}$ Cf. Menke, Ch., La soberanía del arte, Madrid: Visor, 1997, p. 89.

${ }^{63}$ Bowie, A., "The 'German-French' Debate: Critical Theory, Hermeneutics and Deconstruction", en: Knellwolf, Ch. y Ch. Norris (eds.), The Cambridge History of Literary Criticism Volume 9. Twentieth-Century Historical, Philosophical and Psychological Perspectives, Londres: Cambridge University Press, 2008, pp. 121-132. 
y sus derivaciones conceptuales. En conclusión, la intención de mostrar estas discusiones en las extensas lecciones sobre el pensamiento francés de Frank implica poder extender el alcance de los debates en torno a la modernidad y sus legados desde distintas perspectivas y tradiciones.

Recibido: 09/04/2017

Aceptado: 21/04/2018

\section{Bibliografia}

Beiser, F., The Romantic Imperative: The Concept of Early German Romanticism, Cambridge, Mass: Harvard University Press, 2003.

Bowie, A., "The 'German-French' debate: critical theory, hermeneutics and deconstruction" en Knellwolf, C. y otros (eds.), The Cambridge History of Literary Criticism. Twentieth-Century Historical, Philosophical and Psychological Perspectives, Londres: Cambridge University Press, v. IX, 2008, pp. 121-132. https://doi. org/10.1017/CHOL9780521300148.011

Bürger, Ch. y P. Bürger, La desaparición del sujeto, Madrid: Akal, 2001.

De Man, P., La ideología estética, Madrid: Cátedra, 1998.

Derrida, J., Psyche: inventions de 1'autre, París: Gallile, 1988.

Derrida, J., La voz y el fenómeno. Introducción al problema del signo en la fenomenología de Husserl, Valencia: Pre-textos, 1995.

Derrida, J., Introducción a El origen de la geometría de Husserl, Buenos Aires: Manantial, 2000.

Ferraris, M., Historia de la hermenéutica, México D.F.: Siglo XXI, 2005.

Frank, M., Was ist Neostrukturalismus?, Fráncfort d.M.: Suhrkamp, 1984.

Frank, M., What is Neostructuralism?, Minéapolis: University of Minnesota Press, 1989

Frank, M., El dios venidero, Madrid: Ediciones del Serbal, 1994.

Frank, M., La piedra de toque de la individualidad. Reflexiones sobre sujeto, persona $e$ individuo con motivo de su certificado de defunción postmoderno, Barcelona: Herder, 1995.

Frank, M., "Integración sin entusiasmo. La filosofia alemana entre la asimilación y el rechazo de la tradición”, en: Revista de Occidente. Pensar en alemán hoy, 282 (2004a), pp. 5-14.

Frank, M., Dios en el exilio. Lecciones sobre la nueva mitología, Madrid: Akal, 2004b.

Frank, M., The Philosophical Foundations of Early German Romanticism, New York: State University of New York Press, 2004c.

Frank, M., ¿Qué es el neoestructuralismo?, México: FCE, 2011.

Habermas, J., "La modernidad, un proyecto incompleto", en: Foster, H. (ed.), La posmodernidad, Barcelona: Kairós, 1985, pp. 19-36.

Habermas, J., El discurso filosófico de la modernidad, Madrid: Taurus, 1993. 
Hauge, H., “The Will to Consensus: Manfred Frank on Derrida”, en: MLN, v. CV, 3 (1990), pp. 596-609. https://doi.org/10.2307/2905076

Henrich, D., Kunst und Kunstphilosophie der Gegenwart. Überlegungen mit Rüscksicht auf Hegel, Immanente Äesthetik, ästhetische Reflexion, Múnich: Fink, 1966.

Henrich, D., "Selbstbewusstsein, kritische Einleitung in eine Theorie“, en: Bubner, R. y otros (eds.), Hermeneutik und Dialektik (Gadamer-Festschrift), Tubinga: Mohr, 1970, pp. 257-284.

Henrich, D., Vida consciente, Madrid: Sintesis, 2005.

Holub, R., "Review: Was is Neostructuralism?", en: The German Quarterly, v. LIX, 1 (1986), pp. 112-116. https://doi.org/10.2307/406216

Holub, R., "Politicizing Post-Structuralism: French Theory and the Left in the Federal Republic and in the United States", en: The German Quarterly, v. LVII, 1 (1984), pp. 75-90. https://doi.org/10.2307/405209

López, J.L., "¿Tiene la autoconciencia un fundamento lingüístico? Ernst Tugendhat y la Escuela de Heidelberg", en: Logos. Anales del Seminario de Metafisica, v. XLVI, (2013), pp. 77-101.

Menke, Ch., La soberanía del arte, Madrid: Visor, 1997.

Millán, E., Friedrich Schlegel and the Emergence of Romantic Philosophy, Albany: State University of New York Press, 2007.

Pippin, R., "On Not Being a Neo-Structuralist: Remarks on Manfred Frank and Romantic Subjectivity", en: Pippin, R., The persistence of the subjectivity, Nueva York: Cambridge University Press, 2005, pp. 168-185. https://doi.org/10.1017/ CBO9780511614637.009

Raulet, G., La filosofía alemana después de 1945, Valencia: Universidad de Valencia, 2006.

Raulet, G. y otros, "Le siège de la Raison ou une philosophie entre plusieurs chaises. Bilan de la philosophie allemande actuelle", en: Allemagnes d'aujourd'hui, 99/ 100 (1987), pp. 73-97.

Schlegel, F., Fragmentos, seguido de Sobre la incomprensibilidad. Barcelona: Marbot, 2009.

Schwab, M., "Foreword", en: Frank, M., What is Neoestruturalim? Mineápolis: University of Minnesota Press, 1989, pp. X-XLIV. 